\title{
TINJAUAN DYNAMIC GOVERNANCE DALAM MENDUKUNG PENGEMBANGAN PERKAMPUNGAN BUDAYA BETAWI (PBB) SETU BABAKAN MENUJU WISATA HALAL
}

\author{
REVIEW OF DYNAMIC GOVERNANCE IN SUPPORTING \\ DEVELOPMENT OF BETAWI CULTURE SETU BABAP \\ TOWARDS HALAL TOURISM
}

\author{
Hisyam Yusril Hidayat, Dyah Ayu Febriani, Davis Malchiel Ravanelli \\ Fakultas Ilmu Administrasi, \\ Universitas Indonesia \\ hisyam.yusril@ui.ac.id
}

\begin{abstract}
Abstrak
PBB Setu Babakan Betawi sebagai daerah pengembangan budaya betawi terakhir Provinsi DKI Jakarta masih menghadapi berbagai masalah dalam menyediakan fasilitas \& infrastruktur dan mengelola pembangunan ekonomi bagi penduduk setempat. Peraturan saat ini tentang Implementasi Bisnis Pariwisata menjadi dasar pengembangan pariwisata di PBB Setu Babakan sebagai objek wisata halal pertama di Provinsi DKI Jakarta. Indonesia memiliki potensi besar untuk pariwisata halal, terutama provinsi DKI Jakarta yang satu dari sepuluh provinsi akan ditargetkan sebagai tempat wisata halal di Indonesia. Pengembangan pariwisata juga diarahkan menuju pariwisata halal berdasarkan kearifan lokal yang akan berdampak pada peningkatan ekonomi masyarakat sekitar. Hal ini dapat didukung oleh kemampuan dinamis dari para pemangku kepentingan untuk mengadaptasi perubahan lingkungan dan memiliki orientasi berkelanjutan dalam mengatasi berbagai masalah. Kemampuan dinamis adalah salah satu elemen tata kelola dinamis yang mencakup proses thinking again, thinking process, dan thinking across. Tujuan dari penelitian ini adalah untuk menganalisis prospek implementasi tata pemerintahan yang dinamis dalam hal pembangunan PBB Setu Babakan sebagai wisata halal berbasis kearifan lokal. Penelitian ini dikategorikan sebagai deskriptif kuantitatif. Hasilnya menunjukan bahwa dynamic capabilities membantu dalam proses pengembangan wisata halal di PBB Setu Babakan.
\end{abstract}

Kata Kunci: Dynamic Governance, pengembangan wisata, setu babakan, wisata halal.

Abstract
PBB Setu Babakan Betawi as the last betawi cultural development area DKI
Jakarta Province still faces various problems in providing facilities \& 
infrastructure and managing economic development for local residents. The Current Regulation is concerning on the Implementation of Tourism Business became the basis of tourism development in PBB Setu Babakan as the first halal tourism object in DKI Jakarta Province. Indonesia has big potential for halal tourism, especially DKI Jakarta province is one of ten provinces will be targeted as halal tourism spot in Indonesia. Tourism development is also directed towards halal tourism based on local wisdom that will be impacted on improving the economy of the surrounding community. It can be supported by dynamic capabilities of stakeholders to adapt the changes of environment and have a sustainable orientation in overcoming various problems. Dynamic capabilities is one of dynamic governance elements which included process of thinking again, thinking process, and thinking across. The purpose of this study is to analyze the prospect of the implementation of dynamic governance in term of development of PBB Setu Babakan as a local wisdom-based halal tour. This study categorized as quantitative descriptive. The result shows that dynamic capabilities encourage in the process of developing halal tourism in PBB Setu Babakan.

Keywords: dynamic governance, halal tourism, setu babakan, tourism development

\section{A. Pendahuluan}

Sektor pariwisata diketahui banyak berkontribusi bagi perekonomian baik di negara maju maupun berkembang dan berperan penting dalam menciptakan lapangan pekerjaan yang berkelanjutan (Memiş, 2017). Indonesia menjadi salah satu dari negara yang gencar mengembangkan sektor pariwisata hal itu karena menjadi salah satu penyokong pertumbuhan ekonomi (Vaspintra, 2017).

Salah satu bagian dari sektor pariwisata yang saat ini tengah berkembang adalah wisata halal yang memiliki potensi sangat besar di Indonesia. Merujuk Global Muslim Travel Index (GMTI) tahun 2018 dan 2019, Indonesia menduduki peringkat kedua pada tahun 2018 dan di tahun selanjutnya dapat menduduki peringkat pertama sebagai destinasi wisata halal di dunia. Di Indonesia terdapat beberapa provinsi yang dikonsentrasikan menjadi wisata halal unggulan salah satunya adalah Provinsi DKI Jakarta (Kemenkeu.go.id, 2019). Sektor pariwisata merupakan sektor potensial yang dapat dikembangkan di Provinsi DKI Jakarta (Bank Indonesia, 2017).

Sektor pariwisata berkontribusi juga terhadap pendapatan daerah regional bruto (PDRB) Provinsi DKI Jakarta, Trisno Nugroho selaku 
Kepala Bank Indonesia Perwakilan DKI Jakarta mengatakan bahwa sebesar 10 persen dari PDRB DKI Jakarta berasal dari sektor pariwisata dan diprediksi dapat menjadi sumber pertumbuhan baru jika dioptimalkan (Edunews.id, 2019).

Pengembangan sektor pariwisata di Provinsi DKI Jakarta salah satunya diarahkan menjadi wisata halal unggulan, Tim Percepatan Pengembangan Pariwisata Halal Riyanto Sofyan mengatakan bahwa wisata halal di DKI Jakarta sangat potensial diarahkan menjadi destinasi urban yang didukung oleh wisata belanja, wisata kuliner, wisata alam, dan wisata budaya (Jakarta-tourism.go.id, 2019). Salah satu objek wisata di Provinsi DKI Jakarta yang diarahkan menjadi destinasi wisata halal pertama adalah Perkampungan Budaya Betawi (PBB) Setu Babakan. Wisata halal sendiri diartikan sebagai sebuah objek atau aktivitas yang mana diperbolehkan merujuk pada ajaran islam atau ditujukan untuk menarik minat muslim dalam industri pariwisata (Nurdiansyah, 2018).

Pengembangan tersebut didasarkan pada pasal 8 ayat 2 poin C Peraturan Daerah (Perda) Nomor 18 Tahun 2018 yang tentang Penyelenggaraan Usaha Pariwisata. Terdapat berbagai hambatan yang membuat proses pengembangan menjadi tidak berprogresif. Dimulai dari permasalahan pengelolaan PBB Setu Babakan, pembangunan fisik dan non-fisik yang masih belum merata, belum adanya pemberdayaan bagi Usaha Mikro Kecil dan Menengah (UMKM), belum menyejahterahkan masyarakat sekitar, dan jumlah pengunjung yang masih rendah (Maryetti et al., 2016; Vaspintra, 2017; Widaningsih et al., 2019). Selain itu Pengembangan PBB Setu Babakan menjadi wisata halal dimaksudkan untuk tetap mempertahankan eksistensi sebagai satu-satunya kawasan perkampungan betawi namun tetap dapat melakukan adaptasi dengan perkembangan pariwisata yang terjadi pada saat ini. Hambatan tersebut dapat diatasi melalui penerapan dari kerangka dasar dynamic governance. Adapun konsep dynamic governance digunakan di pelbagai sektor seperti kesehatan, pertanian, perikanan, pemerintahan, dan pariwisata (Anwar, 2009, 2011; Gulbrandsen, 2014; Kusuma, 2015; Fauzi and Iryana, 2017; Nurizwan and Dewi, 2018).

Berdasarkan latar belakang masalah, peneliti tertarik untuk mengetahui suatu kemungkinan penerapan dynamic governance dalam pengembangan pariwisata PBB Setu Babakan menjadi wisata halal pertama di Provinsi DKI Jakarta. Adapun rumusan masalah 
yang dibuat adalah sebagai berikut:

1) Bagaimana kemampuan dinamis Pemprov DKI Jakarta dalam mendukung pengembangan $\mathrm{PBB}$ Setu Babakan menjadi wisata halal pertama di Provinsi DKI Jakarta?

2) Bagaimana kesiapan ditinjau dari able people dan agile process dalam mendukung pengembangan $\mathrm{PBB}$ Setu Babakan menjadi wisata halal pertama di Provinsi DKI Jakarta?

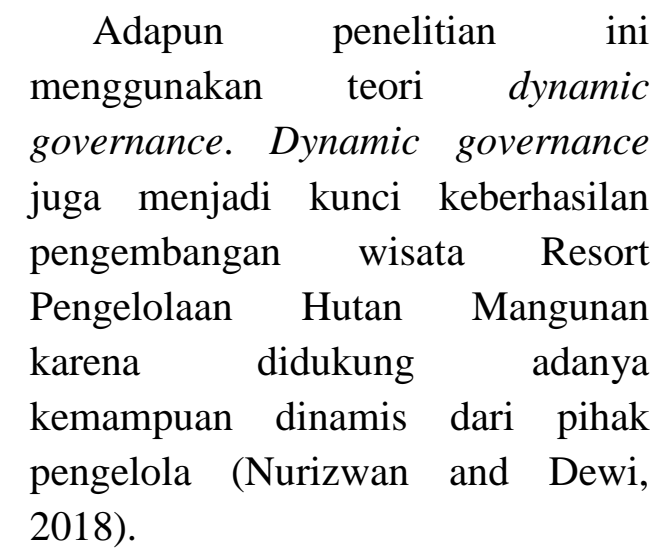

Keberhasilan itu dapat direplikasi dalam kaitannya terhadap pengembangan PBB Setu Babakan menjadi wisata halal pertama. Hal itu dikarenakan keberhasilan dari pengembangan PBB Setu Babakan menjadi wisata halal pertama membutuhkan adanya kemampuan dinamis dari para pihak yang berkaitan dengan pengembangan tersebut. Kemampuan dinamis dipandang sebagai tujuan bersama ke depan, arah, strategi kebijakan, berpikir kreatif, dianggap sebagai agen perubahan yang membuat perkembangan organisasi dapat diwujudkan dan dapat meningkatkan kapabilitas internal dalam merespon faktor-faktor eksternal (Akwei, Peppard and Hughes, 2006; Nurizwan and Dewi, 2018). Kemampuan dinamis mencakup proses thinking ahead, thinking again, dan thinking across dan dipengaruhi oleh able people dan agile process dalam proses suatu kebijakan (Neo and Chen, 2007; Anwar, 2009, 2011).

Menurut (Spillane, 1994) objek wisata dapat dikembangkan apabila memenuhi syarat berikut, yaitu Attraction (keunikan dan menjadi daya tarik wisatawan). Atraksi wisata terdiri dari dua yakni: a) Site Attraction, yaitu daya tarik yang dimiliki oleh objek wisata semenjak objek itu ada. b) Event Attraction, yaitu daya tarik yang dimiliki oleh suatu objek wisata setelah dibuat.

Berkaitan dengan wisata halal terdapat Trend wisata halal memiliki beberapa kriteria kunci untuk menjadikan sebuah wisata dapat dikatakan halal dan menarik perhatian pengujung. Terdapat 10 kunci trend wisata halal meliputi, 1) halal digital economy; 2) Rise of Muslim female travellers; 3) Asian destinations leadership; 4) Development of the halal travel ecosystem; 5) Halal authentication or Muslim-friendly tourist services; 6) Content discovery and halal experiences; 7) Spreading travellers' visual stories; 8) Role of Artificial 
Intelligence (AI) in the development of halal travel solutions; 9) Brand empathy to connect with Muslim travellers; 10) sustainability and community initiatives. (VargasSánchez and Moral-Moral, 2019).

\section{B. Metode Penelitian}

Paradigma dalam penelitian ini adalah post-positivist yang mana menggunakan metode campuran (Morris, J., McNaughton, D., Mullins, R., \& Osmond, 2009). Penelitian ini menggunakan pedoman wawancara sebagai bahan dan alat utama dalam penelitian ini. Peneliti memilih informan yang berasal dari Dinas Pariwisata dan Kebudayaan Pemprov DKI Jakarta, masyarakat, dan UPT PBB Setu Babakan.

Penelitian ini menggunakan metode pengumpulan data kualitatif melalui wawancara mendalam, dokumentasi, studi kepustakaan, dan juga dilengkapi dengan observasi dari kondisi sekitar PBB Setu Babakan. Analisis data adalah suatu proses mengolah, mengevaluasi dan mentransformasi data yang diperoleh dari hasil penelitian sehingga mudah dipahami dan dapat digunakan untuk mengambil kesimpulan yang berguna untuk pembuatan kebijakan dan pengambilan keputusan (Sugiyono, 2010).

\section{Pembahasan}

PBB Setu Babakan terbagi atas lima kawasan yang pertama Zona A dengan luas (3,2 hektar), Zona B (3.771 m2), Zona C (3,2 hektar), Zona Embrio (4.132 m2), dan Zona Pengembangan Sarana dan Prasarana Kebudayaan Betawi (1,9 hektar). Zona A itu sendiri memiliki banyak fasilitas dimulai dari adanya Rumah Kebaya (pusat informasi), Youth Hostel (wisma betawi), Pusat Pendidikan dan Pelatihan Seni Budaya, Museum, Gedung Kesenian dan Serbaguna, Amphitheater dan bangunan rumah adat, pusat kuliner, mushola, kebun buah, empang, jembatan, area rekreasi, parkir, dermaga, toilet umum, dan saung atau gazebo.

Kawasan parkir terbagi atas parkir mobil yang dapat menampung 72 mobil, kapasitas parkir motor yang dapat menampung 120 motor, dan parkir sepeda yang dapat menampung 30 sepeda. Zona B itu terdapat zona busana \& souvenir, area kuliner, service area, toilet, pos keamanan, dan mushola. Terdapat 150-200 pedagang yang berjualan dan itu termasuk 130 pedagang yang telah lama berjualan. Zona C memiliki beberapa perencanaan pembangunan dimulai dari adanya dermaga, resort berjumlah 22unit untuk disewakan, lobby resort, convention hall, main kitchen \& utility, restoran indoor dan outdoor, plaza dan information center, area penjualan barang seni \& makanan asli betawi, area hijau, 
perkampungan budaya betawi empang, dan kandang hewan ternak.

Selain itu, UPK PBB Setu Babakan juga menambahkan bahwa terdapat zona embrio dimana zona tersebut merupakan cikal bakal awal mula berkembangnya PBB Setu Babakan. Di Zona A terdapat museum sejarah Betawi mulai dari pakaian adat, alat musik tradisional, hingga golok terbesar ada di sana. Dalam area seluas 298 hektar, terdapat 3 masjid yang berada dibawah kepengurusan UPK PBB Setu Babakan sebagai salah satu fasilitas bagi para pengunjung dan masyarakat sekitar. PBB Setu Babakan mengusung pengembangan budaya yang tumbuh beriringan dengan lingkungan masyarakat di wilayah Srengseng Sawah, Jakarta Selatan dan menjadikan perkampungan tersebut tumbuh alami sesuai dengan kebudayaan Betawi.

Melalui hasil wawancara yang dilakukan dengan kepala UPK PBB Setu Babakan, Ibu Rofiko, PBB Setu Babakan setiap minggunya dapat menarik pengunjung hingga 3.000 orang dan pada tahun 2018 tercatat terdapat 480.000 pengunjung dalam setahun. Pengunjung kian meningkat melihat bahwa atraksi yang ditawarkan semakin bervariatif dan menarik.

\section{Tinjauan Dynamic Capabilities}

Kapabilitas dinamis menjadi aspek penting dalam kerangka dynamic governance, adapun hal tersebut didorong berdasarkan ketidakpastian mengenai keadaan saat ini dan juga dapat memantik proses thinking ahead dalam pemerintah. Berdasarkan wawancara mendalam dengan pihak Staff Bidang Pemasaran Bagian Pengkajian dan Pengembangan Dinas Pariwisata dan Kebudayaan (Disparbud) Pemprov DKI Jakarta Ibu Agustia Martadiana dan telaah secara daring ditemukan bahwa adanya predikat Indonesia menjadi negara dengan potensi wisata halal yang terbesar di dunia membuat Pemerintah Pusat bahkan mengoordinasikan hingga ke tingkat daerah untuk bersama-sama memanfaatkan potensi wisata halal itu sendiri.

Selain itu di Provinsi DKI Jakarta menjadi empat besar berdasarkan Indonesia Muslim Travellers Index (IMTI) yang mana merupakan hasil ratifikasi dari GMTI yang berlaku dalam skala global dan dibuat atas kerjasama Kementerian Pariwisata dan Crescentrating - Mastercard. IMTI tersebut merujuk hasil wawancara menjadi dasar bagi perencanaan pengemabangan wisata halal di Provinsi DKI Jakarta yang diinisiasi sejak 2018 dan akan rampung pada 2019 ini. Perencanaan berkaitan 
wisata halal ditargetkan akan menghasilkan suatu kajian dan peraturan gubernur khusus pengembangan pariwisata di DKI Jakarta.

Dari proses perencanaan tersebut terlihat proses thinking again yang mana Pemprov DKI Jakarta dapat memahami perkembangan yang ada saat ini dan dapat menyesuaikan dengan agenda dalam skala nasional berkaitan dengan upaya pegembangan wisata halal di Provinsi DKI Jakarta. Proses eksplorasi dari tren tersebut bahkan menghasilkan tujuan yaitu untuk menjadikan Provinsi DKI Jakarta menjadi provinsi dengan potensi terbesar wisata halal di Indonesia pada tahun 2020 yang mana akan diharapkan dapat memberikan dampak ekonomi karena berdasarkan temuan dari Disparbud bahwa wisatawan mancanegara yang berasal dari timur tengah atau mayoritas muslim memiliki spending yang tinggi.

Hingga saat ini Pemprov DKI Jakarta terus melakukan kajian yang ditargetkan rampung Oktober ini, kajian tersebut hingga saat ini masih menekankan pada permasalahan yang berasal dari beberapa indikator IMTI yang masih belum maksimal dilakukan oleh Pemprov DKI Jakarta yaitu berkaitan dengan masalah kesediaan produk dan pelayanan halal. Kajian tersebut dibuat berdasarkan target sampel yaitu 5 restoran dan 1 hotel dari setiap destinasi yang ditargetkan menjadi wisata halal di Jakarta salah satunya adalah PBB Setu Babakan. Kajian tersebut ditujukan untuk menutupi kekurangan mengenai masih minimnya ketersediaan pelayanan dan produk halal yang merupakan kebutuhan dasar para wisatawan muslim. Adapun Disparbud sendiri juga sedang melakukan approaching terhadap penyedia fasilitas perhotelan maupun penginapan dari yang memiliki standar biasa hingga bintang lima agar setidaknya menyediakan fasilitas kitchen halal yang dapat mendukung wisata halal. Pelaku industri rumah makan dan restoran juga sedang dilakukan approach agar dapat menyediakan makanan halal bagi para wisatawan muslim yang berkunjung di DKI Jakarta. Bukan hanya itu Pemprov DKI Jakarta akan memfasilitasi informasi jika para pelaku industri tersebut mau melakukan sertifikasi halal.

Adapun berkaitan dengan proses pengembangan wisata halal di DKI Jakarta, Pemprov tidak mengarahkan untuk merubah secara holistik pelayanan hospitality maupun fasilitas restoran yang sudah ada melainkan hanya mengimbau dan mengajak untuk melakukan extended services atau penambahan pelayanan yang ramah bagi 
wisatawan muslim karena potensinya yang besar. Perwujudan wisata halal juga diturunkan hingga di tingkat UPK PBB Setu Babakan untuk melakukan rencana secara spesifik untuk mendukung kelayakan PBB Setu Babakan menjadi wisata halal di DKI Jakarta. PBB Setu Babakan dipilih menjadi pilot project dalam pengembangan wisata halal dikarenakan menjadi prioritas wisata karena akan dijadikan wilayah original budaya betawi dan karena keunikan budaya tersebut yang mana juga linear dengan prinsip wisata halal sehingga menjadi dasar penetapan untuk hal itu. Proses thinking ahead juga terlihat dari adanya proses penyusunan kajian dan perencanaan yang mana melibatkan koordinasi Kementerian Pariwisata untuk mengintegrasikan program yang ada di pusat dan yang akan dicanangkan oleh Pemprov, koordinasi dilakukan terakhir pada akhir Agustus tahun 2019, dan akan terus dilakukan hingga selesai sesuai target pada akhir akhir tahun ini.

Proses thinking ahead yang dijalankan oleh UPK PBB Setu Babakan sesuai dengan penuturan Kepala Unit Pengelola Kawasan PBB Setu Babakan, Ibu Rofika, bahwa nantinya akan dibuat masterplan dalam pembangunan kawasan PBB Setu Babakan yang sesuai dengan kebutuhan destinasi wisata halal yang diinginkan oleh pemerintah. Dalam hal ini, UPK PBB Setu Babakan telah memiliki konsep tersendiri yang nantinya akan diajukan dan menjadi pertimbangan bagi pemerintah provinsi dalam rangka membuat masterplan bagaimana seharusnya destinasi wisata halal di kawasan PBB Setu Babakan dapat dikembangkan tanpa menghilangkan budaya Betawi yang memang seharusnya menjadi daya tarik utama dan dipertahankan. Selain itu, akan adanya kitchen halal tidak sematamata hanya memenuhi perihal halal dalam agama, tetapi untuk bahan baku makanannya harus melalui uji lab food test agar memenuhi standar. Dalam kebijakan kedepannya, UPK PBB Setu Babakan akan mengupayakan pengelompokkan pedagang dalam satu kawasan yang sudah rapih dan tertib.

Proses thinking again juga dilakukan dalam kaitannya terhadap pengembangan wisata halal di DKI Jakarta. Disparbud melakukan peninjauan ulang peraturan yang sudah ada dan menghasilkan sebuah konklusi bahwa perlu adanya pergub baru yang dapat menjadi dasar perencanaan karena pergub maupun perda yang saat ini dibuat belum memuat mengenai perencanaan wisata halal yang baru muncul sejak 2018. Saat ini juga pengkajian yang dilakukan juga untuk menilai kekurangan dari pariwisata DKI Jakarta. Selain itu juga Disparbud 
melakukan survei kepuasaan pengunjung yang berdasarkan indikator yang dibuat oleh Kementerian Dalam Negeri dan Kementerian Pendayagunaan Aparatur Negara dan Reformasi Administrasi, namun survei tersebut belum dapat memberikan masukan bagi proses pengembangan pariwisata di PBB Setu Babakan, karena pada tahun 2018 belum termasuk yang disurvei, hal itu dikarenakan PBB Setu Babakan belum menjadi daerah yang memiliki jumlah pengunjung banyak di DKI Jakarta. Disparbud juga menerima berbagai masukan dari masyarakat melalui aplikasi CRM, hingga saat ini belum ada pelaporan yang merujuk pada PBB Setu Babakan.

Namun tahun ini akan dilakukan survei tersebut untuk memberikan masukan bagi perbaikan kualitas pelayanan di PBB Setu Babakan. Dapat terlihat dalam hal ini proses thinking again yang dilakukan oleh Disparbud dalam kaitannya terhadap PBB Setu Babakan belum maksimal karena belum memiliki input berdasarkan survei kepuasaan pelanggan yang berasal dari masyarakat. Proses thinking again juga dilakukan, berdasarkan temuan dari Disparbud sejauh ini, dapat diambil kesimpulan bahwa optimalisasi produk yang dihasilkan penduduk maupun UMKM sekitar PBB Setu Babakan belum maksimal hal itu dikarenakan Disparbud menilai produk yang selama ini dihasilkan sebetulnya dapat lebih dikembangkan lagi hingga menghasilkan nilai jual beli.

Peran Disparbud berdasarkan wawancara yang mendalam memiliki limitasi karena sebetulnya pemberdayaan UMKM di sekitar wilayah PBB Setu Babakan menjadi tanggung jawab dari Dinas UMKM di Provinsi DKI Jakarta. Hal tersebut dapat menjadi masukan bagi para pemangku jabatan untuk turut bekerjasama dalam memajukan masyarakat dan UMKM dengan adanya pariwisata yang mana hal tersebut sebetulnya sudah diamanatkan dalam peraturan yang ada. Proses thinking again berkaitan dengan koordinasi ke pemerintah pusat maupun dengan UPK PBB Setu Babakan, sudah berjalan baik karena antarpihak saling terbuka dengan adanya suatu kerjasama dan dibentuknya UPK PBB Setu Babakan di bawah koordinasi Disparbud juga memudahkan pelbagai penyesuaian rencana yang akan dilakukan provinsi terkait dengan pengembangan destinasi wisata yang ada di PBB Setu Babakan. Namun inisiasi untuk dibentuknya pergub sudah tepat hal itu dikarenakan dengan adanya pergub akan memudahkan proses pengembangan pariwisata khususnya di PBB Setu Babakan menjadi lebih mudah. 
Proses thinking across sedang dilakukan oleh Pemprov DKI Jakarta, dalam kaitannya mendukung proses pengembangan pariwisata halal di DKI Jakarta, Disparbud melakukan kerjasama dengan Tim Percepatan dan Pengembangan Kementerian Pariwisata, akademisi, dan pihak industri dalam memaksimalkan proses perencanaan dan kajian yang sedang dilakukan.

Bahkan Disparbud juga melakukan kerjasama dengan pakar dan inisiator wisata halal asal Indonesia yang bekerja di Malaysia yaitu Prof. Irwandi Jaswir untuk mengkaji mengenai faktor-faktor yang dapat mempengaruhi proses pengembangan wisata halal. Berdasarkan temuan hingga saat ini dinyatakan bahwa terdapat perbandingan situasi yang ada di Malaysia dan di Indonesia yang mana ditemukan fakta bahwa di Indonesia dalam proses pengembangan masih lebih mudah dibandingkan Malaysia misalnya dalam melakukan proses sertifikasi jauh lebih rumit proses yang ada di Malaysia. Namun terdapat kondisi serupa antara Malaysia dan Indonesia khususnya di Jakarta, yang mana hingga saat ini masih melakukan proses perumusan peraturan yang dapat menjadi dasar pengembangaan wisata halal.

Namun berkaitan dengan proses pengembangan PBB Setu Babakan belum dilakukan adanya kajian untuk mempelajari praktik yang telah berhasil di negara lainnya yang dapat direplikasi merujuk merujuk hasil wawancara mendalam. Berkaitan dengan proses penciptaan inovatif dari masyarakat dalam membantu pemerintah melaksanakan tugasnya, Disparbud mengatakan bahwa hal tersebut memungkinkan dilakukan karena merujuk pada telaah secara daring juga ditemukan adanya dorongan dari Pemprov DKI Jakarta untuk membentuk pemerintah menjadi government 4.0 yang mana dapat menjadi wadah bagi masyarakat untuk mencetuskan ide terhadap suatu program melalui aplikasi CRM yang mana akan ditindaklanjuti dan dilaksanakan. Selain itu juga Disparbud juga akan mengusung aplikasi yang disebut easy go yang di akhir tahun atau awal tahun nanti akan dirilis. Adapun aplikasi tersebut memiliki fitur unggulan yaitu dapat memuat semua informasi berkaitan dengan amenitas, dan akomodasi pariwisata dari masalah penginapan hingga penyediaan fasilitas tempat makanan yang ada di Jakarta. Satu hal yang spesial dalam aplikasi ini adalah akan ada fitur khusus yang dapat memuat informasi mengenai wisata halal dan penyediaan layanan lainnya yang tentu saja berprinsip pada wisata halal. Dari temuan tersebut dapat terlihat bahwa proses thinking 
across masih belum terlaksana dengan baik karena belum ada kajian untuk perbandingan dengan praktik yang sudah berhasil dan terkhusus aplikasi CRM yang seharusnya digunakan masyarakat juga masih belum memberikan masukan yang signifikan.

\section{Tinjauan Able People}

Ketiga proses yang berkaitan dalam kapabilitas dinamis dapat didukung dengan adanya able people dan agile process. Disparbud sudah cukup memenuhi aspek able people, hal itu terlihat dari adanya Bagian Pengkajian dan Pengembangan Disparbud yang dapat menyesuaikan dengan perencanaan pengembangan pariwisata dengan yang ada tren di tingkat global hingga nasional berkaitan dengan wisata halal. Selain itu berdasarkan hasil wawancara mendalam juga Disparbud juga sebelumnya melakukan beberapa telaah literatur berkaitan dengan pengembangan pariwisata halal.

Selain itu juga dalam mendukung tugasnya Disparbud juga dibantu oleh para akademisi yang dapat memberikan masukan dalam konteks perencanaan dan pengkajian yang sedang dilakukan. Disparbud juga dapat melakukan adaptasi terhadap inisiasi kebijakan pemerintah di tingkat pusat berkaitan dengan optimalisasi potensi wisata halal di Indonesia.
Sebagai salah satu provinsi yang diperhitungkan DKI Jakarta saat ini sedang menyiapkan perencanaan untuk mencapai tujuan menjadi provinsi dengan indeks wisata halal menurut IMTI terbesar pada tahun 2020. Perencanaan yang dilakukan dan peraturan yang sedang dibuat juga sudah cukup tanggap dilakukan, sejak 2018 sudah ada keseriusan dan komitmen di tingkat pemerintah pusat dan pemerintah daerah untuk menyukseskan hingga membuat IMTI yang menjadi guidance dalam proses pengembangan wisata halal yang akan dipastikan rampung di akhir tahun ini. Selain itu sumber daya yang dimiliki khususnya dari Bagian Pengkajian dan Pengembangan Disparbud juga dapat berkoordinasi dengan pelbagai pihak pemerintah pusat hingga pelaku industri.

Dalam konteks yang sama, UPK PBB Setu Babakan selaku pelaksana teknis semakin gencar mengadakan pelatihan dan pengembangan bagi para pengurus UPK PBB Setu Babakan agar dapat memahami perkembangan pariwisata yang ada dan dapat membaca peluang dengan cepat dalam rangka mempertahankan dan mempromosikan budaya betawi terutama dalam hal perencanaan persiapan menuju salah satu destinasi wisata halal yang akan menjadi role model bagi destinasi wisata lainnya di Jakarta. 


\section{Tinjauan Agile Process}

Stabilitas proses menjadi faktor penting yang dapat mempengaruhi kapabilitas dinamis pemerintah. Agile process berkaitan dengan koordinasi, kombinasi, dan integrasi dengan pihak Tim Percepatan Pengembangan Kementerian

Pariwisata sudah berjalan dengan sangat baik, bahkan pihak dari tim tersebut yang terus proaktif dalam membantu pemerintah daerah dalam melakukan proses perencanaan pengembangan wisata halal. Selain itu, proses kerjasama dengan para akademisi dan pelaku industri berdasarkan wawancara mendalam sejauh ini berjalan dengan baik dan antarpihak sudah menyadari potensi wisata halal yang ada sehingga perlu adanya pelibatan untuk dapat memaksimalkan hal tersebut.

Dalam proses pelaksanaan teknis yang dilakukan oleh UPK PBB Setu Babakan proses koordinasi langsung turun dari Disparbud DKI Jakarta, tidak lupa UPK juga mengajak warga msyarakat sekitar area PBB Setu Babakan dalam pengembangan dan pelestarian budaya betawi. Pemberdayaan UMKM dan home industries juga menjadi salah satu bentuk koordinasi untuk menjadikan kawasan PBB Setu Babakan menjadi kawasan betawi yang tumbuh dan berkembang alami.

\section{Tinjauan}

Pariwisata

Rencana pengembangan

pariwisata PBB Setu Babakan menuju wisata halal perlu memperhatikan empat syarat yang dikemukakan oleh (Spillane, 1994) hal tersebut dikarenakan agar pengembangan pariwisata menjadi lebih maksimal. Berkaitan dengan aspek attraction, Setu Babakan sudah memiliki daya tarik yang kuat dari segi alam, budaya, dan kuliner. Tentu saja wisata alam sukar ditemui di Jakarta sehingga Setu Babakan menjadi alternatif wisata di daerah perkotaan. Hal yang dapat dilakukan di area setu mulai dari sekadar duduk di sekitar danau menikmati pemandangan ataupun sambil menyantap makanan karena posisinya sangat dekat dengan pedagang ataupun juga memancing.

Selain itu dari segi budaya juga sebagai kawasan terpadu untuk pelestarian budaya betawi satusatunya di Jakarta sehingga setiap orang baik itu wisatawan lokal maupun mancanegara yang ingin mengetahui seluk beluk betawi apakah itu dari sejarah, budaya, makanan harus berkunjung ke tempat ini. Berdasarkan wawancara dengan Kepala UPK PBB Setu Babakan, event attraction perlu ditingkatkan dengan mengadakan acara yang menarik tidak hanya melibatkan sanggar tetapi juga komponen masyarakat untuk 
menarik minat wisatawan lokal dan mancanegara untuk datang.

\section{Tinjauan Tren Wisata Halal}

Secara mendasar wisata halal menekankan adanya penyediaan kebutuhan khusus wisatawan Muslim terkait dengan fasilitas untuk beribadah dan makanan halal yang mana menjadi salah satu indikator suatu objek wisata memenuhi strategi pemasaran wisata halal. PBB Setu Babakan dalam hal ini sudah dapat memenuhi standar tersebut, hal itu dibuktikan dengan adanya ketersediaan mushola yang berjumlah dua di wilayah Zona $\mathrm{C}$ dan terdapat Masjid Baitul Mamur di dekat wilayah tersebut. Berdasarkan observasi tidak terstruktur ditemukan bahwa fasilitas di mushola di Zona memiliki kapasitas yang sangat sedikit, namun dari segi kualitas air untuk wudhu sudah baik. Di mushola tersebut tidak terdapat tempat penitipan barang untuk wisatawan.

Tinjauan berdasarkan 10 kunci tren wisata halal menurut (VargasSánchez and Moral-Moral, 2019), dimulai dari aspek halal digital economy hingga sustainability and community. Berkaitan dengan aspek halal digital economy, dalam hal ini belum dilaksanakan hal itu dikarenakan fokus pemerintah saat ini adalah dengan melakukan approaching berbagai pihak untuk meningkatkan kualitas produk dan layanan yang berprinsip halal. Sehingga produk dan layanan yang ada akan dapat sesuai dengan kebutuhan wisatawan muslim, selain itu adanya rencana launching aplikasi easy go juga menjadi salah satu potensi pengembangan ekonomi digital berbasis halal karena dapat turut mempromosikan produk halal dan layanan halal yang akan ditawarkan.

Kebutuhan khusus bagi perempuan adalah ketersediaan ruang menyusui yang mana hal tersebut linear dengan kewajiban penyediaan ruang laktasi di tempat publik dan perusahaan merujuk pada Surat Keputusan Bersama (SKB) tiga menteri yaitu Menteri Kesehatan, Menteri Pemberdayaan Perempuan dan Perlindungan Anak, dan Menteri Tenaga Kerja dan Transmigrasi. Hal tersebut juga dikonfirmasi oleh Disparbud bahwa penyediaan ruang laktasi atau menyusui adalah bagian dari kewajiban berkaitan dengan hak asasi manusia yang dimiliki oleh bayi dan ibu. Berkaitan dengan pengembangan ekosistem wisata halal, Disparbud hingga saat ini tengah melakukan approaching kepada industri skala kecil maupun besar agar dapat melirik pasar wisatawan muslim, namun perlu adanya penyesuaian untuk memanfaatkan potensi tersebut seperti dengan melakukan sertifikasi halal dan hingga penyediaan kitchen 
halal hingga di level hotel bintang lima. Disparbud juga terus berkomitmen untuk membantu memberikan dan menyebarkan informasi berkaitan dengan proses sertifikasi halal dan potensi wisata halal di Jakarta yang akan menguntungkan berbagai pihak.

Berdasarkan temuan dari kajian yang sedang dilakukan oleh Disparbud dapat terlihat bahwa hingga saat ini Provinsi DKI Jakarta masih belum memiliki banyak fasilitas hotel yang berbasis prinsip halal dan bahkan masih belum memiliki kitchen halal, oleh karena itu hingga tahun ini tengah mengupayakan pendekatan ke industri penginapan maupun restoran untuk membuat integrasi pelayanan di semua sektor pariwisata dan perhotelan. Hingga saat ini belum tersedia platform yang dapat memuat konten mengenai wisata halal yang disediakan oleh Pemprov DKI Jakarta, hal tersebut menjadi salah satu hambatan yang mana membuat wisatawan muslim kesulitan mencari kebutuhannya. Namun hal tersebut akan diatasi dengan diluncurkannya fitur easy go di tahun ini. Hal tersebut juga dapat menjadi sebuah inovasi teknologi yang dapat menguntungkan khususnya bagi promosi destinasi halal di Jakarta.

\section{Penutup}

PBB Setu Babakan sebagai destinasi wisata halal mulai dikembangkan menyesuaikan dengan kebutuhan real yang ada di area PBB Setu Babakan. Dinas Pariwisata dan Kebudayaan (Disparbud) DKI Jakarta kini sedang memformulasikan kebijakan mengenai percepatan pembuatan masterplan dalam rangka mewujudkan PBB Setu Babakan menjadi salah satu destinasi wisata halal di Jakarta pada tahun 2020 mendatang. Tidak hanya itu, Disparbud juga mengadakan studi atau pembelajaran lebih lanjut dengan menyiapkan tim ahli untuk membuat kebijakan yang nantinya melandasi PBB Setu Babakan menjadi destinasi wisata halal tepat sasaran, selaras, dan tanpa menghilangkan pelestarian budaya betawi di PBB Setu Babakan.

Disparbud juga sedang berusaha membuat masterplan sebagai pondasi realisasi kebijakan sesuai dengan konteks halal dalam meningkatkan minat kunjungan wisata lokal maupun internasional dengan mengembangkan kemudahan akses, peningkatan fasilitas teknologi dengan platform easy go, ketersediaan fasilitas sarana ibadah, penyedian makanan halal yang nantinya akan diuji melalui lab food test, hingga mengadakan koordinasi dan kolaborasi dengan berbagai pihak terkait dalam menjadikan PBB Setu Babakan menjadi salah satu destinasi wisata halal. Dalam proses 
perencanaan ini sudah ada penerapan dynamic governance.

Rekomendasi yang dapat diberikan oleh peneliti guna meningkatkan proses dynamics governance dalam pengembangan PBB Setu Babakan menjadi destinasi wisata halal adalah:

1) Perlu ditingkatkannya koordinasi dan kolaborasi tidak hanya oleh Dinas Pariwisata dan Kebudayaan DKI Jakarta kepada UPK PBB Setu Babakan, tetapi juga perlu diaadakannya kolaborasi dengan Dinas Bina Marga dalam rangka menyediakan fasilitas perbaikan ingrastruktur jalan guna mencapai Setu Babakan, Dinas tata air DKI Jakarta dalam rangka mengelola adanya setu, serta pemberdayaan UMKM yang seharusnya dikoordinasikan lebih lanjut untuk pembinaan pedagang UMKM di area Setu Babakan

2) Tidak hanya semata-mata mengikuti trend, tetapi pemerintah juga harus siap mengikuti perkembangan trend wisata halal yang ada mulai dari pemenuhan perkembangan teknologi yang ramah pengguna dan mudah digunakan, penyediaan serta peningkatan fasilitas sarana dan prasarana, membina warga sekitar area PBB Setu Babakan, serta menunjang perkembangan PBB Setu Babakan dengan membantu promosi, peningkatan kapasitas, dan kapabilitas kemampuan pengurus
UPK PBB Setu Babakan itu sendiri.

\section{Daftar Pustaka}

Akwei, C., Peppard, J. and Hughes, P. (2006) 'The process of creating dynamic capabilities: a grounded theory approach', in The Practice of Dynamic Capabilities, The Organizational and Knowledge Network Workshop, pp. 221235.

Anwar, R. (2009) Pengembangan Model tentang Pengaruh Able People dan Agile Process terhadap Dynamic Capabilities dalam Proses Kebijakan Publik (Studi Kasus Pelayanan Bidang Pendidikan di Kabupaten Jembrana, Propinsi Bali), Disertasi) Fisip Ilmu Administrasi. Depok: Universitas Indonesia.

Anwar, R. (2011) 'Development of Dynamic Capabilities of Education Service Policy Processes in Jembrana, Bali', Bisnis \& Birokrasi Journal, 17(3).

Bank Indonesia (2017) Kajian Ekonomi Keuangan Regional Agustus 2018, Kajian Ekonomi Keuangan Regional Agustus 2018.

Edunews.id (2019) 'Jakarta Tourism Forum: Sinergi Pengembangan Pariwisata DKI Jakarta'. Available at: https://www.edunews.id/news/j akarta-tourism-forum-sinergi- 
pengembangan-pariwisata-dkijakarta.

Fauzi, L. M. and Iryana, A. B. (2017) 'Strategi Dynamic Governance dalam Penyelenggaraan Pemerintahan Provisi Jawa Barat', MODERAT: Jurnal Ilmiah Ilmu Pemerintahan, 3(3), pp. 13-30.

Gulbrandsen, L. H. (2014) 'Dynamic governance interactions: Evolutionary effects of state responses to non-state certification programs', Regulation \& Governance. Wiley Online Library, 8(1), pp. 74-92.

Jakarta-tourism.go.id (2019) 'DKI Jakarta Masuk Destinasi Wisata Halal, Cek Indikasinya'. Available at: http://jakartatourism.go.id/2017/news/2019/ 02/dki-jakarta-masukdestinasi-wisata-halal-cekindikasinya.

Kemenkeu.go.id (2019) 'Indonesia Becomes World's Best Halal Tourism Destination 2019'. Available at: https://www.kemenkeu.go.id/e $\mathrm{n}$ /publications/news/indonesiabecomes-worlds-best-halaltourism-destination-2019/.

Kusuma, B. M. A. (2015) 'Urgensi Dynamic Governance dalam Meningkatkan Profesionalisme Manajemen Penyelenggaraan Haji', in Dakwah Annual Conference Yogyakarta.
Maryetti, M. et al. (2016) 'The Implementation of Sustainable Tourism Object Development Model at Betawi Village Setu Babakan South Jakarta', in Asia Tourism Forum 2016-the 12th Biennial Conference of Hospitality and Tourism Industry in Asia. Atlantis Press. Memiş, S. (2017) 'Halal Tourism Practices As A Marketing Type: The Example Of Birun Kümbet Mountain Hotel', TURAN-SAM. Sage Yayınları, 9(35), pp. 45-50.

Morris, J., McNaughton, D., Mullins, R., \& Osmond, J. (2009) 'Postpositivist epistemology’.

Neo, B. S. and Chen, G. (2007) Dynamic

Governance: Embedding Culture, Capabilities And Change In Singapore (English Version). World Scientific.

Nurizwan, S. and Dewi, U. (2018) 'Dynamic Governance dalam Pengembangan Pariwisata di Kawasan Resort Pengelolaan Hutan Mangunan Kabupaten Bantul', NATAPRAJA, 6(2), pp. 193-204.

Spillane, J. (1994) Pariwisata Indonesia, Siasat Ekonomi dan Rekayasa Kebudayaan. Yogyakarta: Kanisius.

Sugiyono (2010) Metode Penelitian Pendidikan Pendekatan

Kuantitatif, kualitatif, dan $R \& D$. Bandung: Alfabeta.

Vargas-Sánchez, A. and Moral- 
Moral, M. (2019) 'Halal

tourism: state of the art', Tourism Review. Emerald Publishing Limited.

Vaspintra, P. Z. (2017) Preserving by Selling? The Contestation Between the Notions of Cultural Tourism and Heritage Conservation (A Case Study in Setu Babakan, Jakarta, Indonesia).

Widaningsih, T. T. et al. (2019) 'Carrying Capacity of Betawi Setu Babakan Cultural Tourism Area a Case Study in South Jakarta, Indonesia', Journal of Economics, Management and Trade, pp. 19. 
Spirit Publik Volume 14, Nomor 2, 2019 Halaman 136-153

P-ISSN. 1907-0489 E-ISSN 2580-3875 